\title{
A Comparative Study of Total Albumin and Calcium Level between Preeclamptic Women Undergoing Magnesium Sulfate Therapy and with Normal Pregnancies
}

\author{
Elham Askary $^{1 *}$, Fatemeh Sadat Najib², Tahereh Poordast ${ }^{2}$, \\ Fatemeh Emami ${ }^{1}$ and Mojdeh Momtahan ${ }^{2}$
}

${ }^{1}$ Chief Resident of Obstetrics and Gynecology, OB GYN Department, Faghihi Hospital, Shiraz, Iran. ${ }^{2}$ Associated Professor in Obstetrics and Gynecology, Shiraz University of Medical Sciences, Shiraz, Iran

DOI: http://dx.doi.org/10.13005/bbra/1879

(Received: 10 June 2015; accepted: 25 August 2015)

\begin{abstract}
Magnesium sulfate is used for seizure therapy and profilaxy in women with eclampsia and preeclampsia worldwide. Magnesium has effect on calcium modulation and also there are antithesis reports about alternation between magnesium sulfate therapy and decreased serum calcium level. Decreased in serum calcium level may cause some complications. The present study determines whether maternal serum level of calcium and albumin in patients with preeclampsia are lower than matched control subjects. Thirty patients with preeclampsia who were candidate for received magnesium sulfate therapy compared with 30 normal pregnant women as a control group. Serum calcium and albumin concentration were determined in $3 \mathrm{ml}$ of venous blood sample that was taken before magnesium sulfate therapy, during and $24 \mathrm{hrs}$ after discontinuation of therapy in preeclamptic women and also before and $8 \mathrm{hrs}$ after delivery in normal pregnant women. Findings show no significance difference of maternal and gestational ages between the two groups. The change in mean concentration of albumin, total calcium level, and corrected serum calcium level was observed just significantly at the albumin level $24 \mathrm{hrs}$ after the termination of therapy in preeclamptic group $(3 \mathrm{mg} / \mathrm{dl}, 2.7 \mathrm{mg} / \mathrm{dl})$ $\mathbf{P}=0.03$. There is no any correlation between others items in two groups. In both two groups serum calcium level is more before delivery than after. In the preeclamptic group $(9.1 \mathrm{mg} / \mathrm{dl}, 9 \mathrm{mg} / \mathrm{dl}) \mathrm{P}=0.00$ and in normotensive group $(9.3 \mathrm{mg} / \mathrm{dl}, 9 \mathrm{mg} / \mathrm{dl}) \mathrm{P}=0.00$. According to this small group study magnesium sulfate therapy in preeclamptic women doesn't redounded to change in serum calcium level, but may lead to increased albumin level after delivery in control subject and also after discontinuation of the therapy in patients groups respectively.
\end{abstract}

Keywords: Preeclampsia, Calcium, Albumin, Magnesium sulfate

Preeclampsia has a high prevalence among pregnant women and it can lead to serious complications for them or even death ${ }^{1,2}$. Magnesium sulfate is a common cure for prevention the eclampsia in these patients ${ }^{3}$. Ionic calcium is antagonized by magnesium ions $\mathrm{s}^{4,5}$. Therefore, it seems that magnesium sulfate can

\footnotetext{
* To whom all correspondence should be addressed. Te.l : +989171127112;

E-mail: Elliaskary_md@yahoo.com
}

decrease serum calcium and its adverse effects in preeclamptic patients. Decreased calcium serum is associated with some different effects such as convulsion, muscle spasm especially in the larynx, psychological problems, change in vital signs, and cardiac arrest; so that, it can potentially threaten life $^{6}$. There are also some controversial reports on low calcium contents in preeclamptic patients ${ }^{7-10}$. In case of low calcium contents, magnesium sulfate can intensify the condition and cause serious complications $^{6}$. Halhali et al. (2001) showed that preeclamptic patients have a low level of 
parathormone and injection of magnesium sulfate can increase Calcitonin gene related peptide in them which leads to hypocalcemia ${ }^{11}$. Huang et al. (2004) injected magnesium sulfate to pregnant women with high blood pressure and calculated serum calcium 4 hrs later. They observed that serum calcium is decreased significantly ${ }^{12}$. Cruikshank et al. (1981) observed that treatment of preeclamptic women leads to $25 \%$ decrease in total calcium and $12 \%$ decrease in ionic calcium ${ }^{13}$. Therefore according to the above literature, our study was aimed to evaluate the serum calcium levels as well as albumin (which transport a large amount of calcium in serum) in preeclamptic women who were receiving magnesium sulfate and they compared with women with normal blood pressure. Results of current study present valuable information about serum calcium levels and useful approaches for treatment of preeclamptic patients.

\section{MATERIALSAND METHODS}

This study was a double blinded clinical trial study. Our cases were 60 pregnant women referred to Hazrat Zainab Hospital (Shiraz, Iran) during 2014. They gave birth with cesarean section. Their BMI were coordinated with each other. The cases were chosen randomly. Certain criteria were considered to participate eligible cases in the study, including: pregnant women with preeclampsia, pregnant women with normal blood pressure, single fetus pregnancy, age range of $15-49,28-48^{\text {th }}$ week of pregnancy. There were also certain criteria to dismiss cases out of the study, Including

Development of eclampsia, and underlying diseases such as renal failure, endocrine disorders, cardiovascular disorders, and collagen vascular disease.

After coordination of patients' BMI, $3 \mathrm{ml}$ venous blood was taken from each case in control group (normal blood pressure group) $(\mathrm{n}=30)$ at two time points ( 2 hrs before delivery and $48 \mathrm{hrs}$ after delivery). These blood samples were sent to the Hospital Laboratory within $1 \mathrm{hr}$ in order to assess total calcium and albumin levels. Control group received normal saline $1 \mathrm{Lit} / 24 \mathrm{hrs}$ for 2 days after delivery; in cases who had no limitation for receiving this volume. Serum calcium level was assessed for preeclampsia group $(\mathrm{n}=30) 2 \mathrm{hrs}$ before delivery, 8 hrs after initiating treatment with magnesium sulfate (which was simultaneous with delivery) and 24 hrs after end of magnesium sulfate treatment. Magnesium sulfate treatment lasted for $24 \mathrm{hrs}$, intravenously (initial dose $=4 \mathrm{gr}$, maintenance dose $=2 \mathrm{gr} / \mathrm{h}$ ). There were some patients in whom magnesium sulfate made some side effects and their treatment was cut. These patients were excluded from study. The level of corrected calcium was calculated according to the Eq. (1) as follows:

Corrected $\mathrm{Ca}(\mathrm{mg} / \mathrm{dL})=$ measured total serum Ca $(\mathrm{mg} / \mathrm{dL})+[4.0$ - serum $\mathrm{Al}(\mathrm{g} / \mathrm{dL}) \times 0.8](1)$ where $\mathrm{Ca}$ denotes calcium and $\mathrm{Al}$ albumin.The data were analyzed with statistical package SPSS (version 17) using descriptive assessments. The data were expressed as mean \pm standard deviation. Kolmogorov Smirnov test was used to check normal distribution of data. For the normal distribution, paired t-test and Student's ttest was used to compare the same group pre- and post-treatment and the two different groups, respectively. For the non-normal distribution, Wilcoxon test and Mann-Whitney U test was used for intra-group and intergroup, respectively. The $\mathrm{P}$ values lower than 0.05 were considered as significance level.

\section{RESULTS}

The demographic information of the patient is presented in Table 1 . The groups were the same regarding all variables and had no significant difference ( $p>0.05$ ), expect that for pregnancy stage $(p=0.001)$

In control group, total calcium and albumin levels of serum were significantly higher at pre-delivery assessment compared to postdelivery assessment. However, corrected calcium level according to albumin was higher at postdelivery assessment compared to pre-delivery assessment, but it was not significant (Table 2).

In preeclampsia group, serum albumin level was significantly higher at pre-delivery assessment compared to the time in which treatment with magnesium sulfate was running and 24 hrs after intervention. There was no significant difference between the time in which treatment with magnesium sulfate was running and the time-point after treatment (table 3). There was also a higher 
content of total calcium at pre-treatment assessment compared to the time in which treatment with magnesium sulfate was running and 24 hrs after, although it was not significant. Calcium level was significantly higher at the time in which treatment with magnesium sulfate was running

Table 1. Basic information of pregnant women before delivery

\begin{tabular}{lllc}
\hline Variable & Group & Mean & Standard Deviation \\
\hline \multirow{2}{*}{ Age } & Control & 29.2 & 4.8 \\
\multirow{2}{*}{ Weight $(\mathrm{kg})$} & Preeclampsia & 29.8 & 7.6 \\
\multirow{2}{*}{ Height (m) } & Control & 76.6 & 13.01 \\
& Preeclampsia & 79.6 & 15.6 \\
Average number of pregnancies & Control & 161.4 & 5.3 \\
& Preeclampsia & 161.4 & 8.1 \\
\multirow{2}{*}{ Pregnancy stage (week) } & Control & 1.9 & 0.3 \\
& Preeclampsia & 1.4 & 0.5 \\
& Control & 38.3 & 0.9 \\
& Preeclampsia & 35.6 & 3.2 \\
\hline
\end{tabular}

Table 2. Intra-group comparison of blood pressure in control group

\begin{tabular}{llccc}
\hline & Variable & Mean $^{2}$ & Standard deviation $^{2}$ & $\mathrm{P}^{1}$ \\
\hline \multirow{2}{*}{ Pair 1 } & Pre-delivery albumin & 3.2 & 0.4 & 0.001 \\
& Post-delivery albumin & 2.7 & 0.3 & \\
\multirow{2}{*}{ Pair 2 } & Pre-delivery calcium & 8.6 & 0.6 & 0.02 \\
& Post-delivery calcium & 8.2 & 0.5 & \multirow{2}{*}{0.8} \\
& Pre-delivery corrected calcium & 8.9 & 1.6 & \\
& Post-delivery corrected calcium & 9.3 & 0.7 & \\
\hline
\end{tabular}

${ }^{1}$ Wilcoxon test $\quad{ }^{2} \mathrm{mg} / \mathrm{dl}$

Table 3. Intra-group comparison of preeclampsia group

\begin{tabular}{|c|c|c|c|c|}
\hline & Variable regarding to the time-point of treatment & Mean & Standard Deviation & $\mathrm{P}^{1}$ \\
\hline \multirow[t]{2}{*}{ Pair 1} & Pre-treatment Albumin & 3.2 & 0.4 & $0.00^{*}$ \\
\hline & Post-treatment Albumin & 3.0 & 1.1 & \\
\hline \multirow[t]{2}{*}{ Pair 2} & Pre-treatment Albumin & 3.2 & 1.0 & $0.00 *$ \\
\hline & During-treatment Albumin & 3.0 & 0.4 & \\
\hline \multirow[t]{2}{*}{ Pair 3} & Post-treatment Albumin & 3.0 & 1.1 & $0.2^{*}$ \\
\hline & During-treatment Albumin & 3.0 & 0.7 & \\
\hline \multirow[t]{2}{*}{ Pair 4} & Pre-treatment Calcium & 8.5 & 0.8 & 0.00 \\
\hline & Post-treatment Calcium & 8.0 & 0.8 & \\
\hline \multirow[t]{2}{*}{ Pair 5} & Pre-treatment Calcium & 8.5 & 0.8 & 0.046 \\
\hline & During-treatment Calcium & 8.2 & 0.7 & \\
\hline \multirow[t]{2}{*}{ Pair 6} & Post-treatment Calcium & 8.0 & 0.8 & 0.05 \\
\hline & During-treatment Calcium & 8.2 & 0.7 & \\
\hline \multirow[t]{2}{*}{ Pair 7} & Pre-treatment Corrected Calcium & 9.1 & 0.7 & 0.01 \\
\hline & Post-treatment Corrected Calcium & 9.0 & 0.8 & \\
\hline \multirow[t]{2}{*}{ Pair 8} & Pre-treatment Corrected Calcium & 9.1 & 0.7 & 0.9 \\
\hline & During-treatment Corrected Calcium & 9.2 & 0.6 & \\
\hline \multirow[t]{2}{*}{ Pair 9} & During-treatment Corrected Calcium & 9.2 & 0.6 & 0.2 \\
\hline & Post-treatment Corrected Calcium & 9.0 & 0.8 & \\
\hline
\end{tabular}

${ }^{1}$ Paired t-test *Wilcoxon test 
compared to after intervention $(p=0.046)$. Corrected calcium level was also higher at pre-delivery assessment compared to 24 hrs after intervention, although it was not significant.

Our results indicated that serum albumin level was higher in preeclampsia group compared to control group, although it was not significant except in the case of 24 hrs after treatment with magnesium sulfate. Serum total calcium level of control group was higher than preeclampsia group, both before and after intervention; however, it was not significant. There was no significant difference between two groups neither before nor after intervention, regarding corrected calcium level (Table 4). Comparison of pre-treatment, duringtreatment and post-treatment assessments showed no significant difference regarding serum calcium, albumin and corrected calcium levels.

Table 4. Inter-group comparison based on time-point of treatment with magnesium sulfate

\begin{tabular}{|c|c|c|c|c|c|}
\hline Variable & Group & Mean Changes & Mean & Std. Deviation & $\mathrm{P}^{1}$ \\
\hline \multirow[t]{2}{*}{ Pre-treatment Albumin } & Control & 0.0 & 3.2 & 0.4 & 0.9 \\
\hline & Preeclampsia & & 3.2 & 0.4 & \\
\hline \multirow[t]{2}{*}{ Post-treatment Albumin } & Control & -0.3 & 2.7 & 0.3 & $0.03 *$ \\
\hline & Preeclampsia & & 3.0 & 1.1 & \\
\hline \multirow[t]{2}{*}{ Pre-treatment Calcium } & Control & +0.1 & 8.6 & 0.6 & 0.7 \\
\hline & Preeclampsia & & 8.5 & 0.8 & \\
\hline \multirow[t]{2}{*}{ Post-treatment Calcium } & Control & +0.2 & 8.2 & 0.5 & $0.3^{*}$ \\
\hline & Preeclampsia & & 8.0 & 0.8 & \\
\hline \multirow[t]{2}{*}{ Pre-treatment Corrected Calcium } & Control & -0.2 & 8.9 & 1.6 & $0.9 *$ \\
\hline & Preeclampsia & & 9.1 & 0.7 & \\
\hline \multirow[t]{2}{*}{ Post-treatment Corrected Calcium } & Control & +0.3 & 9.3 & 0.7 & 0.1 \\
\hline & Preeclampsia & & 9.0 & 0.8 & \\
\hline
\end{tabular}

${ }^{1}$ Student's t-test *mann-whitney U test

\section{DISCUSSION}

Magnesium sulfate is widely used for preventing convulsion in pregnant women with preeclampsia. However, the exact mechanism is still unclear, but it seems that this drug takes its protecting effect via various ways, including: vasodilator effect on brain blood vessels, decreasing resistance of brain and peripheral blood vessels, protecting blood-brain barrier of brain and spine which leads to attenuation of cerebral edema ${ }^{3}$. Moreover, magnesium is involved in regulation of calcium. Therefore, the current study was aimed to comparatively evaluate the serum calcium and albumin levels between pregnant women with preeclampsia and their counterparts with normal blood pressure.

Our results showed that there was no significant difference between magnesium sulfate received group (preeclampsia group) regarding calcium level, neither before nor after intervention. However after treatment with magnesium sulfate, albumin level was significantly higher in intervention group compared to control group. Additionally, serum calcium and albumin levels during treatment had no significant change compared to pre-delivery and post-delivery timepoints.

Similarly, Apostol et al. (2010) observed that injection of magnesium sulfate to preeclamptic women does not cause a significant change in calcium level, compared to women with normal blood pressure ${ }^{14}$. On the other hand, Cruikshank et al. (1981) showed that treatment with magnesium sulfate leads to decrease in total and ionic calcium levels in preeclamptic women compared with women with normal blood pressure, so that parathormone hormone was increased in their serum which in turn caused excretion of urine calcium $^{15}$.

Discussions on calcium role in preventing preeclampsia still exist ${ }^{16}$. Both magnesium and calcium ions are important in maintenance of muscle cells membrane electrical activities, including vascular muscles which are involved in preeclampsia pathophysiology. Calcium is essential 
for muscle contraction and is antagonized by magnesium. Beside direct interaction, magnesium opposes calcium function via inhibition of calcium releasing from sarcoplasmic reticulum, returning back the calcium ion from intra-cellular matrix to the sarcoplasmic reticulum and competing calcium ions to bind myosin active sites. All of these processes lead to reduction of smooth muscle contraction $^{4,5,17,18}$.

In addition previous clinical studies have demonstrated vasodilatory effect of magnesium on bronchial smooth muscle during asthma attacks ${ }^{19}$. Furthermore, low levels of serum magnesium is associated with increased contraction of small and large coronary arteries and intensified response to stimuli such as norepinephrine, potassium, acetyl choline, serotonin, and angiotensin ${ }^{20}$. Magnesium deficiency takes part in developing brain ischemia and its proper level has a protective role ${ }^{21}$. It is also well known that magnesium (magnesium chloride and magnesium sulfate) depolarizes muscle cells and endothelium of placenta arteries. It has even a stronger effect than nifedipine which is a calcium channel blocker ${ }^{22}$. In other word, magnesium can potentially fight against pathophysiology and systemic complications of preeclampsia.

According to antagonism between calcium and magnesium ions, it seems that treatment with magnesium sulfate leads to decrease in serum calcium level of preeclamptic mothers which in turn predispose condition to development of preeclampsia and eclampsia ${ }^{23-25}$. These reports conflicted with our findings. This controversy may be explained by this fact that magnesium exerts its effect via intra-cellular calcium and it has no impact on extra-cellular calcium ${ }^{26}$. Moreover, contraction of myometrium is under control of various hormonal and chemical mediators ${ }^{3}$. These causes can affect contraction process of placental vessels ${ }^{27}$, 28 . In another word, controlling a single factor such as calcium blocking would not be the only effective factor in development of preeclampsia or intensifying the condition. However, it seems that reduction of calcium increases the risk of development of preeclampsia, especially in women with high blood pressure ${ }^{23,29}$. Ali et al. (2007) reported that magnesium sulfate has no effect on sever preeclampsia and eclampsia patients. They suggested that protective drug regimen is not associated with changes in serum calcium levels ${ }^{30}$. However, various studies reported controversial results on serum calcium level in preeclamptic patient compared to individuals with normal blood pressure and there are still some ambiguities ${ }^{7-10,31 \text {, }}$ ${ }^{32}$. In cases of preeclamptic pregnant women in which serum calcium level was low, increase in urine calcium and high levels of parathormone was identified as the main cause ${ }^{7,10}$. In our results, there was also no difference before, during and after the intervention. We also found that in women with normal blood pressure, calcium level is significantly higher before pregnancy compared to postdelivery assessment. However after calculating the corrected calcium level according to albumin ${ }^{33}$, this difference was not significant which is consistent with Gertner and Roelofsenl studies ${ }^{34,35}$.

We found that treatment of re-eclampsia women with magnesium sulfate had no significant effect on serum albumin level compared to predelivery/post-delivery women with normal blood pressure. Serum albumin level of preeclampsia group was also higher at 24 hrs after intervention compared with the control group. It is well documented that urine protein excretion is an index for predicting eclampsia severity, preterm mortality and severity of these patients' high blood pressure $^{36}$. It is believed that reduction of albumin in preeclampsia condition is the result of liver ischemia and also an early sign of development of preeclampsia ${ }^{37}$. In contrast to our study, another cohort study by Salako et al. showed that preeclamptic pregnant women have a higher level of albumin compared to pregnant women with normal blood pressure ${ }^{38}$. On the other hand, Salari et al. and Makuyana found that there is no significant difference between these two groups, which was in accordance with our study ${ }^{39}, 40$. Increasing albumin $24 \mathrm{hrs}$ after the intervention is probably due to vasodilatory properties of magnesium as well as delivery (as the preferred treatment of preeclampsia in order to remove the toxic condition) lead to improvement of liver function which in turn recovers albumin synthesis and release within 48 hrs after delivery. In this regard, a previous study showed that inhalation of nitric oxide (which has vasodilatory properties) improves liver function within 24 hours after liver transplantation ${ }^{41}$. From another point of view, 
magnesium had a liver-protecting effect after delivery in preeclamptic women.

One of limitations in our study was the inclusion and exclusion criteria which resulted in decrease of our studied population. Other limitations of the study were lack of assessment of serum parathormone, serum vitamin $\mathrm{D}$, urine Calcium and urine magnesium. Assessment of these factors and their effect could present a better insight, but it was not performed because of financial limitations. However, assessment of these factors was not among the main purpose of the study. These factors can be considered in future related studies to increase the purity and certainty of results.

Finally, our results showed that although magnesium sulfate decreased serum calcium during and after the intervention compared to preintervention condition (within group) and its decrease during treatment is negligible $(p=0.047)$, but it had no significant difference with control group. In essence, treatment with magnesium sulfate in preeclamptic patients had no impact on serum calcium level and it is not necessary to modify the level of this ion in patients.

\section{ACKNOWLEDGEMENTS}

This paper is issued from a part of the thesis submitted to the school of medicine in partial fulfillment of the requirements for the degree of specialty in obstetrics and gynecology.

\section{REFERENCES}

1. Jeyabalan A. Epidemiology of preeclampsia: Impact of obesity. Nutr Rev. 2013; 71(01):S18S25.

2. Hoedjes M, Berks D, Vogel I, Franx A, Bangma M, Darlington AS, et al . Postpartum depression after mild and severe preeclampsia. $J$ Womens Heal. 2011; 20(10): 1535-42.

3. Euser AG, Cipolla MJ. Magnesium sulfate for the treatment of eclampsia: a brief review. Stroke. 2009; 40(4):1169-75.

4. Gilbert D’Angelo EK, Singer HA, Rembold CM. Magnesium relaxes arterial smooth muscle by decreasing intracellular $\mathrm{Ca}^{2+}$ without changing intracellular $\mathrm{Mg}^{2+}$. J Clin Invest. 1992; 89(6):1988-94.

5. Young RC, Smith LH, McLaren MD. T-type and L-type calcium currents in freshly dispersed human uterine smooth muscle cells. Am J Obstet Gynecol. 1993;169(4):785-92.

6. Schafer AL, Fitzpatrick LA, Shoback DM. signs of hypocalcemia chvostek and trousseau signs. Hosp Physician .2000; 36(3):43-45

7. Gasnier R, Valério EG, Vettorazzi J, Barros EG, Martins-Costa SH, Ramos JGL. Calciuria and preeclampsia: A case-control study. J Obstet Gynaecol Res. 2012; 38(4):674-80.

8. Sandip S, Asha K, Paulin G, Hiren S, Gagandeep S, Amit V. A comparative study of serum uric acid , calcium and magnesium in preeclampsia and normal pregnancy. Journal of Advance Researches in Biological Sciences.2013; 5(1): 55-8.

9. Vahid-Roodsari F, Ayati S, Torabizadeh A, Ayatollahi H, Esmaeli H, Shahabian M. Serum calcium and magnesium in preeclamptic and normal pregnancies; A Comparative Study. $J$ Reprod Infertil. 2008; 9(3): 256-62

10. Malas NO, Shurideh ZM. Does serum calcium in preeclampsia and normal pregnancy differ? Saudi Med J. 2001; 22(10): 868-71.

11. Halhali A, Wimalawansa SJ, Berentsen V, Avila E, Thota CS, Larrea F. Calcitonin gene- and parathyroid hormone-related peptides in preeclampsia: Effects of magnesium sulfate. Obstet Gynecol. 2001;97(6):893-7.

12. Nechifor M, Vaideanu C, Palamaru I, Borza C, Mindreci I. The influence of some antipsychotics on erythrocyte magnesium and plasma magnesium, calcium, copper and zinc in patients with paranoid schizophrenia. Journal of the American College of Nutrition. 2004; 23(5): 549S-551S.

13. Cruikshank DP, Pitkin RM, Donnelly E, Reynolds WA. Urinary magnesium, calcium, and phosphate excretion during magnesium sulfate infusion. Obstet Gynecol. 1981;58(4):430-4.

14. Apostol A, Apostol R, Ali E, Choi A, Ehsuni N, $\mathrm{Hu} \mathrm{B}$, et al . Cerebral spinal fluid and serum ionized magnesium and calcium levels in preeclamptic women during administration of magnesium sulfate. Fertil Steril. 2010; 94(1): 276-82.

15. Cruikshank D,Pitkin RM,Donnelly E BA, Reynolds W A. Urinary Magnesium, Calcium and Phosphate exertion during magnesium sulfate infution.Obstetric and Gynecology 1981; 58(4): 430-4.

16. López-Jaramillo P. Calcium, nitric oxide, and preeclampsia. Semin Perinatol. 2000; 24(1): 336.

17. Iseri LT, French JH.Magnesium: nature's physiologic calcium blocker. American heart journal.1984; 108(1): 188-93. 
18. Altura BM, Altura BT, Carella A, Gebrewold A, Murakawa T, Nishio A. Mg2+-Ca2+ interaction in contractility of vascular smooth muscle: Mg2+ versus organic calcium channel blockers on myogenic tone and agonist-induced responsiveness of blood vessels. Can J Physiol Pharmacol. 1987;65(4):729-45.

19. Gourgoulianis KI, Chatziparasidis G, Chatziefthimiou A, Molyvdas PA. Magnesium as a relaxing factor of airway smooth muscles. $J$ Aerosol Med. 2001;14(3):301-7

20. Turlapaty PD, Altura BM. Magnesium deficiency produces spasms of coronary arteries: relationship to etiology of sudden death ischemic heart disease. Science. 1980; 208(4440): 198200.

21. Tong GM, Rude RK. Magnesium deficiency in critical illness. J Intensive Care Med [Internet]. 2005;20:3-17. Available from: http:// www.ncbi.nlm.nih.gov/pubmed/15665255.

22. Bara M, Guiet-Bara A. Magnesium regulation of $\mathrm{Ca} 2+$ channels in smooth muscle and endothelial cells of human allantochorial placental vessels. Magnes Res. 2001;14(1-2):11-8.

23. Hofmeyr GJ, Roodt A, Atallah AN, Duley L. Calcium supplementation to prevent preeclampsia-a systematic review. S Afr Med J. 2003; 93(3): 224-8.

24. Hofmeyr GJ, Lawrie TA, Atallah AN, Duley L. Calcium supplementation during pregnancy for preventing hypertensive disorders and related problems. Cochrane Database Syst Rev. 2010; 8(8): 1-86.

25. Hofmeyr GJ, Duley L, Atallah A. Dietary calcium supplementation for prevention of preeclampsia and related problems: a systematic review and commentary. Br J Obstet Gynaecol. 2007; 114(8): 933-43.

26. Zhang A, Fan SH, Cheng TPO, Altura BT, Wong RKS, Altura BM. Extracellular Mg2+ modulates intracellular $\mathrm{Ca} 2+$ in acutely isolated hippocampal CA1 pyramidal cells of the guineapig. Brain Res. 1996; 728(2): 204-8.

27. Mandalà $\mathrm{M}$, Gokina $\mathrm{N}$, Osol G. Contribution of nonendothelial nitric oxide to altered rat uterine resistance artery serotonin reactivity during pregnancy. Am J Obstet Gynecol. 2002; 187(2): 463-8.

28. Schooley MC, Franz KB. Magnesium deficiency during pregnancy in rats increases systolic blood pressure and plasma nitrite. Am J Hypertens. 2002; 15(12): 1081-6.

29. Hofmeyr GJ, Duley L, Atallah A. Dietary calcium supplementation for prevention of preeclampsia and related problems: A systematic review and commentary. BJOG: An International Journal of Obstetrics and Gynaecology. 2007; 114(8): 933-43.

30. Aali S, Khazaeli P, Ghasemi F, Mehdizadeh A. Serum magnesium and calcium ions in patients with severe preeclampsia/eclampsia undergoing magnesium sulfate therapy. Med Sci Monit. 2007; 13(9): CR191-R194.

31. Kim J, Kim YJ, Lee R, Moon JH, Jo I. Serum levels of zinc, calcium, and iron are associated with the risk of preeclampsia in pregnant women. Nutr Res. 2012; 32(10): 764-9.

32. Indumati V, Kodliwadmath M V , Sheela M K. The role of serum electrolytes in pregnancy induced hypertension the role of serum electrolytes in pregnancy induced hypertension. Journal of Clinical and Diagnostic Research. 2011: 5(1): 66-9.

33. Sharp CR, Kerl ME, Mann FA. A comparison of total calcium, corrected calcium, and ionized calcium concentrations as indicators of calcium homeostasis among hypoalbuminemic dogs requiring intensive care: Original study. $J$ Vet Emerg Crit Care. 2009;19(6):571-8.

34. Roelofsen JM, Berkel GM, Uttendorfsky OT, Slegers JF. Urinary excretion rates of calcium and magnesium in normal and complicated pregnancies. Eur J Obstet Gynecol Reprod Biol. 1988; 27(3):227-36.

35. Gertner JM, Coustan DR, Kliger AS, Mallette LE, Ravin N, Broadus AE. Pregnancy as state of physiologic absorptive hypercalciuria. Am J Med. 1986; 81(3):451-6.

36. Homer CSE, Brown MA, Mangos G, Davis GK. Non-proteinuric preeclampsia: a novel risk indicator in women with gestational hypertension. J Hypertens. 2008; 26(2): 295302.

37. Gojnic M, Petkovic S, Papic M, Mostic T, Jeremic K, Vilendecic Z, et al. Plasma albumin level as an indicator of severity of preeclampsia. Clinical and Experimental Obstetrics and Gynecology. 2004; 31(3): 209-10.

38. Salako BL, Odukogbe a T, Olayemi O, Adedapo KS, Aimakhu CO, Alu FE, et al. Serum albumin, creatinine, uric acid and hypertensive disorders of pregnancy. East Afr Med J. 2003;80(8):4248.

39. Salari Z,Eftekhari N,Taj Al-Dini M. Assessment level of phosphate,albumin and total protein in preeclampsic patient and normal pregnancy. $J$ of Kerman UMS.2006;13(4):209-14.(Persian)

40. Makuyana D, Mahomed K, Shukusho FD, Majoko F. Liver and kidney function tests in normal and preeclamptic gestation-a 
comparison with non-gestational reference values. The Central African journal of medicine. 2002; 48(5-6): 55-9.

41. Lang JD, Teng X, Chumley P, Crawford JH,
Isbell TS, Chacko BK, et al . Inhaled NO accelerates restoration of liver function in adults following orthotopic liver transplantation. J Clin Invest. 2007; 117(9): 2583-91. 